NASA Technical Memorandum 86728

NASA-TM-86728

19850024811

\title{
Application of Frequency Domain Handling Qualities Criteria to the Longitudinal Landing Task
}

\section{Shahan K. Sarrafian and Bruce G. Powers}

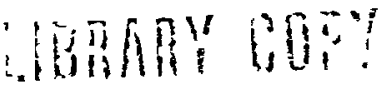

Sef 6 is 95

I. ' LLLY hLSELRCH CEHTEK

LIS- A? r, INMSA

"AMPILN, VIrigithla

August 1985 
31176001879379 


\section{Application of Frequency Domain Handling Qualities Criteria to the Longitudinal Landing Task}

Shahan K. Sarrafian and Bruce G. Powers

Ames Research Center, Dryden Flıght Research Facılity, Edwards, Calıfornıa

\section{N/Sก}

Natıonal Aeronautıcs and

Space Administration

Ames Research Center

Dryden Flıght Research Facility

Edwards, California 93523 


\section{APPLICATION OF FREQUENCY DOMAIN HANDLING QUALITIES CRITERIA TO THE LONGITUDINAL LANDING TASK}

Shahan K Sarrafian* and Bruce G Powers $\dagger$ NASA Ames Research Center, Dryden Flight Research Facility Edwards, California

\section{Abstract}

In recent years, advances in flight controls technology have resulted in the use of elaborate fly-by-wire systems that provide stability augmentation for both transport and high-performance aircraft with static instability Pitch-rate command/attitude-hold systems are typically employed for this purpose and are used on such modern alrcraft as the $F-16, X-29$, and Shuttle In the flared landing task, however, these systems have exhibited floating and ballooning tendencies which result in handling qualities results that are inconsistent with classical predictive criteria

Under NASA sponsorship, an in-flight simulation of the longitudinal handling qualities of several configurations for the approach and landing task was performed on the USAE/AFWAL Total In-Flight Simulator by the Calspan Corporation The basic configuration was a generic transport airplane with static instability The control laws included proportional plus integral gain loops to produce pitch-rate command/attitude-hold systems which were evaluated with and without prefilters Conventional response characteristics were obtained by using pitch-rate and angle-ofattack feedback loops The evaluation task was a conventional visual approach to a flared touchdown at a designated spot on the runway with a lateral offset

The general conclusions were that the existing criteria are based on pitch-attitude response and that these characteristics do not adequately discriminate between the good and bad configurations of this study. This paper describes the work that has been done to further develop frequency-based criteria in an effort to provide better correlation with the observed data

\section{Nomenclature}

$\mathrm{F}_{\text {es }}=$ longitudinal stick force, $\mathrm{lb}$

$h_{p}=$ altitude at pilot station, $f t$

$h_{p_{c}}=$ altitude at pilot station command, $f t$

$\dot{\mathrm{h}}_{\mathrm{p}}=$ altitude rate at pilot station, $\mathrm{ft} / \mathrm{sec}$

"Aerospace Engineer. Member AIAA

†Senior Aerospace Engineer Member AIAA

This paper is declared a work of the U S Government and therefore is in the public domain

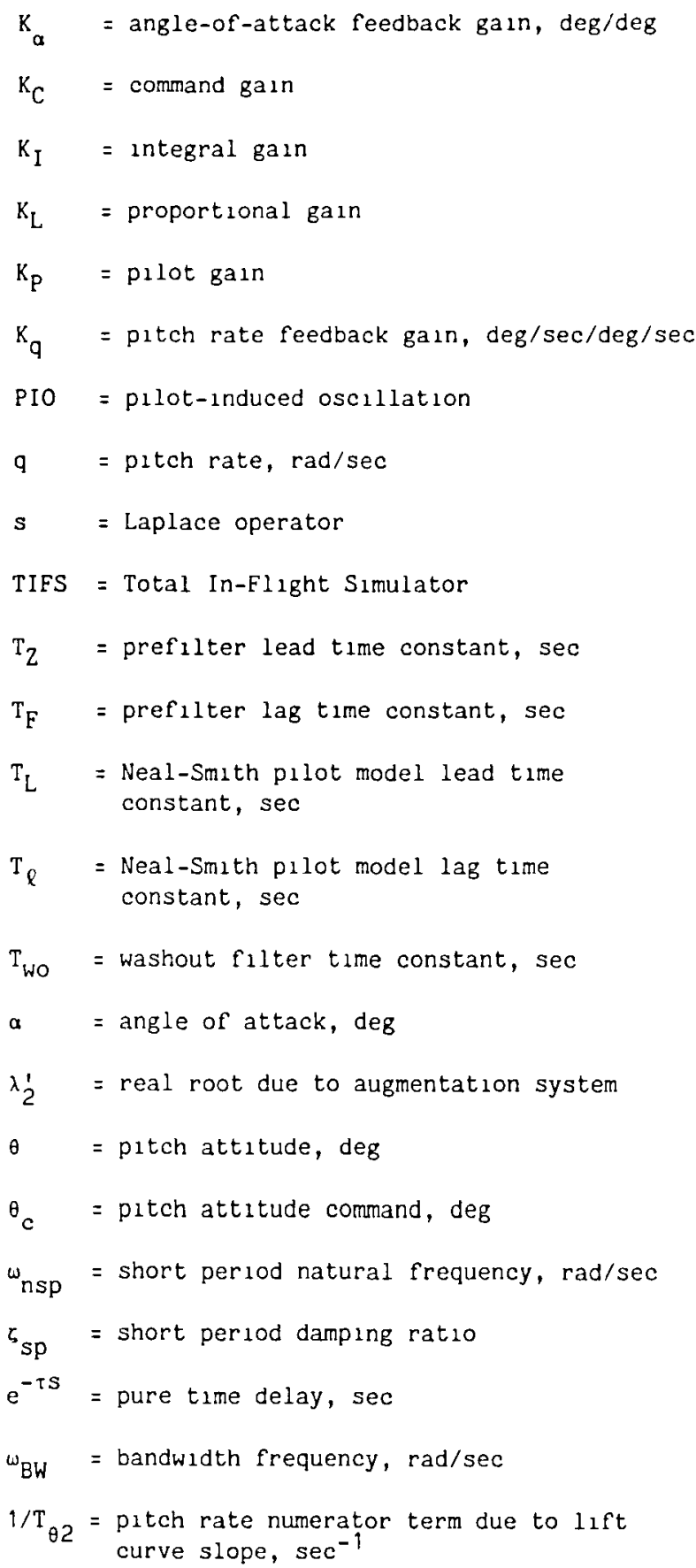

\section{Introduction}

In recent years, advances in flight controls technology have resulted in the use of elaborate fly-by-wire systems that provide stability augmentation for both transport and high-performance 
a1rcraft with static instability. Pitch-rate command/attitude-hold systems are typically employed for this purpose and are used on such modern alrcraft as the F-16, X-29, and Shuttle. In the flared landing task, however, these systems have exhibited floating and ballooning tendencles Longitudinal PIO tendencies have also been observed on occasion when pilots attempt tight closed-loop control with such systems. The resulting aircraft characteristics yielded handling qualities results which have not been consistent with classical predictive criteria. Clearly, these longitudinal predictive criteria need to be refined for better correlation with handling qualities results obtained from the use of such stability augmentation systems.

Under NASA sponsorship, an in-flight simulation of the longitudinal handling qualities of several configurations for the approach and landing task was performed on the USAF/AFWAL Total In-Flight Simulator (TIFS) by the Calspan Corporation, Buffalo, NY The experiment description and results are presented in Ref 1 . The basic configuration was a generic transport airplane with static instability Seven aerodynamic configurations were obtained by varying the lift curve slope, static stability, and lift due to elevator characteristics. Eight variations of control laws were used with the seven aerodynamic models to produce $27 \mathrm{flight-control/airplane} \mathrm{configurations}$ for the study. The control laws included proportional plus integral gain loops to produce pitchrate command/attitude-hold systems which were evaluated with and without prefilters. Conventional response characteristics were obtained by using pitch-rate and angle-of-attack feedback loops The evaluation task was a conventional visual approach to a flared touchdown at a designated spot on the runway A 300-ft lateral offset and a discrete vertical gust were used to increase pilot workload

The general conclusions of the study presented in Ref. 1 were that the existing criteria are generally based on pitch-attitude response and that these characteristics do not adequately discriminate between the good and bad configurations of this study A time-domain criterion was developed based on angle of attack and normal acceleration at the pilot station, and improved correlation was shown A frequency-domain criterion based on sink rate at the pilot station was also shown to be a slight improvement over the pitchattitude criteria This paper describes the work that has been done to further develop frequencybased criteria in an effort to provide better correlation with the observed data

\section{Configuration Set Description}

The configurations evaluated during the in-flight simulation used a flight-control system of a generic transport which is presented in block dlagram form in Fig. 1. A summary of the configurations in terms of the $q / F_{\text {es }}$ transfer function is presented in Table 1 other transfer functions for these configurations are presented in Ref. 1. The pilot ratings assigned to the configurations are based upon the Cooper-Harper rating scale (NASA TN D-5153). A brief description of each configuration set is presented below. These configuration sets are the primary database for the various frequency-doma in criteria applications in this paper

\section{Set 1 Configuration}

Set 1 consisted of three pitch-rate feedback configurations with proportional plus integral paths The short period was set at

$\omega_{n s p}=28 \mathrm{rad} / \mathrm{sec}$ and $\zeta_{\mathrm{sp}}=08$ The pitchrate numerator term $\left(1 / \mathrm{T}_{\theta 2}\right)_{\text {was }}$ set at 038,072 , and 1.0

\section{Set 2 Configurations}

Set 2 contained two pitch-rate feedback configurations with proportional plus integral paths. The short period was set at $\omega_{\text {nsp }}=18 \mathrm{rad} / \mathrm{sec}$ and $c_{\text {sp }}=06$ The pitchrate numerator term $\left(1 / \mathrm{T}_{\theta 2}\right)$ was set at 038 and 0.72 .

\section{Set 3 Conf igurations}

Set 3 included two neutral-static-stability configurations obtained by removing the integrator in the forward path and modifying the aircraft model, which resulted in a first-order pitch-rate response $1 / T_{\theta 2}$ was set at 038 and 072

\section{Set 4 Configurations}

Set 4 consisted of set 1 with the addition of a lead/lag prefilter designed to cancel the control system zero at $K_{I}$ and the augmented real root $\lambda_{2}^{\prime}$ near $1 / T_{\theta 2}$. Configuration 4-3-7-1 added a washout filter in series with the lead/lag prefilter. The washout filter canceled the integrator root of the augmented system at frequencies below $02 \mathrm{rad} / \mathrm{sec}$.

\section{Set 5 Configurations}

Set 5 consisted of set 2 with the lead/lag prefilter

\section{Set 6 Configurations}

Set 6 contained four pitch-rate feedback configurations with high proportional plus integrator gain in the forward path. The basic configuration had a $1 / T_{\theta 2}=038$ The other configurations consisted of basic plus washout, basic plus prefilter, and basic plus washout and prefilter 


\section{Set 7 Configuration}

Set 7 included one "conventional" configuration obtained by using angle of attack and pitchrate feedback loops with one of the neutral-static stabllity alrcraft models.

\section{Set 8 Configurations}

Set 8 consisted of five "Shuttle-11ke" configurations with a $1 / T_{\theta 2}=0.40$. Four of the models placed the pilot $10 \mathrm{ft}$ behind the center of rotation. The fifth model was a canard configuration that placed the pilot $54 \mathrm{ft}$ forward of the center of rotation. The first four models were also evaluated with the washout filter used in sets 4 and 6 .

\section{Pitch-Attitude Frequency-Domain Criterion}

The Neal-Smith theory ${ }^{2}$ is widely used to analyze the closed-loop pitch-attitude control of alrcraft. This method assumed pitch-attitude control to be the primary task of the pilot. An overview of the Neal-Smith theory is presented below. This is intended as a review for those somewhat familiar with Neal-Smith theory For a more thorough explanation of the Neal-Smith theory, see Ref. 2.

\section{Technique Description}

The Neal-Smith theory is based upon a singleloop closure performed on pitch attitude using a pilot model that employs a lead/lag filter with a gain and time delay. This closure technique is shown in Fig 2 The pilot model operates on a pitch-attitude error signal which is the difference between the commanded attitude and the alrcraft's attitude The pilot strategy for the Neal-Smith theory is shown in Fig 3. The pilot, through the flying parameters he is observing, tries to achieve a certain "standard of performance" which is defined by a certain closed-loop bandwidth The bandwidth is defined by the $90^{\circ}$ closed-10op phase requirement. At frequencies below the bandwidth, the pilot attempts to minimize tracking errors as defined by a minimum lowfrequency droop (no more than $-3 \mathrm{~dB}$ ) The pilot also attempts to minimize the closed-loop resonant peak $\|\theta / \theta\|_{\text {max }}$, which minimizes oscillatory tendencies. The lead/lag filter (which is generally a pure lead term for most configurations) and pilot gain are adjusted such that the $-3 \mathrm{~dB}$ droop and $-90^{\circ}$ of closed-loop phase conditions are met for a given bandwidth while the closed-loop resonance is minimized These parameters then provide a measure of compensation with which the pilot closes the loop The process of obtaining these closed-loop conditions is readily displayed on a Nichols chart. The Nichols chart overlays the open-loop amplitude vs phase grid with the closed-loop amplitude vs phase grid Thus, the Nichols chart provides instant information regarding the closed-loop performance (unity feedback is assumed). An example of a successful Neal-Smith solution on a Nichols chart is shown in Fig 4 Once the closed-loop conditions are met, closedloop resonance and pilot lead/lag for a given bandwidth are plotted on a Neal-Smith parameter plane $(\|\theta / \theta\|$ vs pilot compensation) as shown in Fig 5 and then correlated with the pilot ratings for a longitudinal task Figure 5 illustrates the revised Neal-Smith boundaries that were developed in Ref. 3 for the longitudinal landing task

\section{Application of Pitch-Attitude Frequency-Doma in} Criterion

The Neal-Smith analysis performed on the in-flight simulation database showed that a number of configurations were predicted by the criterion to be better than the actual pilot ratings had indicated. 1 A bandwidth of $2.0 \mathrm{rad} / \mathrm{sec}$ produced the most representative correlation between the predicted and actual pilot ratings in this analysis. Although the Neal-Smith criterion is a function of both closed-loop resonance and pilot lead/lag, at this bandwidth the configurations generally exhibited satisfactory levels of closedloop resonance As a result, it appeared that the variations in the actual pilot ratings were primarily dependent upon the amount of pilot lead compensation required to achieve the Neal-Smith closed-loop requirements. Figure 6 lllustrates the relationship between the actual pilot ratings and the pilot lead in pitch attitude required at a bandwidth of $20 \mathrm{rad} / \mathrm{sec}$ In addition to the configurations from Ref 1 , selected configurations from Ref 4 comparable to those from Ref. 1 are shown in Fig. 6. These selected configurations, those of a large aircraft with a short-aft tall, are summarized in Table 2 The pilot ratings for these configurations refer only to the landing performance The \pm 1 pilot rating boundaries in Fig. 6 result in a data correlation of $55 \%$ Note that Fig 6 shows a significant amount of scatter in the data for a wide range of pilot lead compensation

The results from Fig. 6, however, display some trends worth noting The actual pilot ratings appear to degrade as the amount of lead compensation required by the pilot increases for the given bandwidth This is to be expected, as the pilot would like to achieve the highest possible bandwidth with the least amount of compensation The basic configurations with pitch rate feedback (sets 1,2,6-1) appear to require more lead compensation than the same configurations with the lead/lag prefilter. The lead/lag prefilter appears to reduce the amount of lead compensation required by the pilot at the given bandwidth (sets 4,5,6-2) Thus, as the prefilter restores the configuration's original $1 / T_{02}$, the amount of pllot lead required is reduced and this results in improved pilot ratings The conventional configuration (set 7) which consistently produced level I pilot performance 5 required relatively little lead compensation, as did some of the prefilter configurations. The Shuttle-like 
configurations (set 8 ) generally required the largest amount of lead compensation and displayed degraded pilot ratings. Most of the configurations that included a washout filter (the fourdigit configurations) were rated better than would be expected based on the amount of pilot lead required, this is caused by the washout frequency range being below $02 \mathrm{rad} / \mathrm{sec}$, which is considerably below the given bandwidth for pitch attitude Most of the configurations from Table 2 correlated well with the trend in Fig. 6 The overall indications from $F_{1 g} 6$ point out that pitch-attitude characteristics alone are not the primary variable for the flared landing task.

\section{Alt 1 tude-Rate Frequency-Domain Criterion}

Pilot comments indicated that altitude rate control was a significant factor in the evaluation of touchdown performance. ${ }^{1}$ An attempt was made in Ref 1 to close the loop directly on altitude rate at the pilot station using a pilot model which operated with a gain and time delay. A relationship was found between the altitude-rate bandwidth and the actual pilot ratings, which showed only a slight improvement over the pitch-attitude criteria As a result, an alternate method to evaluate altitude-rate control was developed as described in the following section

\section{Technique Description}

Assuming that the pilot closes the loop on altitude rate in a manner similar to pitch attitude, an investigation was made into the closedloop performance of altitude rate using the NealSmith technique Figure 7 illustrates the loop closure in block diagram form Altitude rate at the pilot station is controlled directly using a pilot model which employs a lead filter with a gain and time delay, as in Neal-Smith theory The closed-loop requirements, as before, were $-3 \mathrm{~dB}$ of droop and $-90^{\circ}$ of phase at the given bandwidth This method was then applied to the database

\section{Application of Altitude-Rate Criterion}

As with the Neal-Smith technique, this method uses a closed-loop bandwidth as one measure of pilot performance After several iterations, an altitude-rate bandwidth of $1.3 \mathrm{rad} / \mathrm{sec}$ appeared to best represent the data In general, the maximum resonance at this bandwidth was low for the configurations, and the amount of pllot lead for altitude-rate control appeared to be the dominating factor in the pilot model Figure 8 shows the relationship between the actual pilot ratings and the amount of pilot lead in altitude rate Also included in Fig 8 are the configurations from Table 2 As with pitch-attitude lead, the actual pilot ratings appear to degrade as the requirement for altitude-rate lead increases for the given bandwidth The \pm 1 pilot ratings boundaries show a data correlation of $60 \%$, a slight improvement over the pitch-attitude analysis Note that $F_{1 g} 8$ shows an improvement in the data scatter relative to the pitch-attitude data in Fig 6

The altitude-rate lead requirements in Fig 8 appear to discriminate a number of the configurations. The basic configurations with pitch-rate feedback (sets $1,2,6-1$ ) generally require more lead in altitude rate than the same configurations with a lead/lag prefilter (sets 4,5,6-2) This trend corresponds with the actual pilot ratings The conventional configuration (set 7) displayed an altitude-rate lead representative of the prefilter configurations. The Shuttle-11ke configurations (set 8) generally showed higher lead requirements and correlated well with the actual pilot ratings. The washout configurations (the four-digit configurations) were generally rated better than the altitude-rate lead requirements would indicate, which is again due to the lowfrequency feature of washout filter The configurations from Table 2 showed poor correlation with the trend shown in Fig 8. Despite this point, the trends mentioned above echoed those found with the pitch-attitude lead requirements

The relationship between the pilot ratings from this database and the results from the single-loop closure techniques have provided some insight into the flying qualities obtained with these configurations. However, the results from these single-loop closure techniques do not appear to give an accurate picture of the longitudinal landing task It is possible that control of more than one parameter is required by the pilot to achieve satisfactory performance in this instance, the pilot may elect to control one parameter in series with another during the long1tudinal landing task.

\section{Altitude Criterion with Attitude Inner-Loop Closure}

In an effort to obtain a criterion that would better encompass the wide range of characteristics found in this database, an investigation was made into the closed-loop performance of the pllot using multiloop control. This technique assumes that the pilot controls altitude through pitch attitude to provide satisfactory longitudinal control during landing.

\section{Technique Description}

In the instance when the pilot desires to control altitude, this task is performed by closing an inner loop on pitch attitude and an outer loop on altitude In this way an altitude error is translated into a pitch command Figure 9 shows the closure technique in block diagram form The pitch-attitude loop can be closed using the classical Neal-Smith approach with a pilot model consisting of a lead/lag filter with a gain and time delay The altitude outer loop can then be closed through a pllot model operating with a pure gain 
Following the closure of the pitch-attitude loop, the altitude loop was closed to determine the bandwidth available for altitude control The altitude bandwidth is the frequency at which a satisfactory level of closed-loop resonance (2-4 dB) at $-90^{\circ}$ of closed-loop phase is achleved. A typical altitude outer-loop closure is shown on a Nichols chart in Fig 10.

Application of Altitude Criterion with Attitude Inner-Loop Closure (Attitude Bandwidth Fixed)

An example of this multiloop technique is found in Ref. 4. This method specifies the inner loop as a result of the Neal-Smith attitude closure at a given bandwidth. The multiloop technique of Ref. 4 was applied to the observed data, and the resulting altitude bandwidths for the configurations were plotted against the corresponding actual pilot ratings, as shown in F18. 11 The inner-loop attitude bandwidth remained at $20 \mathrm{rad} / \mathrm{sec}$ for all configurations (since this correlated best, as indicated earlier) Also included in $\mathrm{F}_{1 \mathrm{~g}} .11$ are the configurations from Table 2. Overall, the results from $E 1 \mathrm{~g} .11$ show a data correlation of $64 \%$ within \pm 1 pilot rating This is a slight improvement over the two previous single-10op closure techniques However, the data in Fig 11 do not show adequate continuity and separation throughout the bandwidth range. The basic configurations with pitch-rate feedback (sets $1,2,6-1$ ) do not adequately show the improvement (higher altitude bandwidth) found in the actual pilot ratings with the addition of the lead/lag prefilter (sets 4,5,6-2) The conventional configuration (set 7) displayed one of the higher attainable bandwidths The Shuttle-like configurations (set 8 ) displayed some of the lower bandwidths Two of these configurations (8-2-5, 8-3-5-1) deviated significantly from the observed trends The Shuttle-like canard configuration (8-4-6) was assigned a pilot rating of 1 and had the highest attainable bandw1dth (2 $75 \mathrm{rad} / \mathrm{sec})$ Most of the configurations from Table 2 were not consistent with the trend observed in Fig 11

A possible shortcoming of this method is that the inner-loop attitude compensation is based upon a given bandwidth The pilot may not need all the attitude compensation provided by some of the configurations at this given bandwidth Ideally, the pilot will attain an inner-loop bandwidth which provides adequate inner-loop control such that he may then control the outer loop The inner-loop bandwidth will then vary for each configuration This must be taken into account when applying a multiloop technique of this type to handling qualities data

Application of Altitude Criterion with Attitude Inner-Loop Closure (Attitude Lead Compensation F1xed)

The focal point of this paper is the technique of defining the inner-loop pilot model such that the altitude performance characteristics can be defined by a single metric For the configurations of this study, pllot lead compensation is required to improve the pitch-attitude control. However, it is assumed that this pilot compensation in pitch is provided to ensure good altitude characteristics rather than a good attitude "tracker," as such Therefore, in order to provide a consistent inner-loop strategy between configurations, it is assumed that the pilot will provide an amount of inner-loop pitch-attitude lead consistent with level I handling qualities and then examine the resulting altitude outer-loop performance. From Fig. 5, it can be seen that $25^{\circ}$ of lead compensation is consistent with level I pilot ratings The inner-loop pilot model (lead and gain) was then determined from the classical Neal-Smith solution that provided $25^{\circ}$ of lead compensation (which corresponds to a bandwidth of $18 \mathrm{rad} / \mathrm{sec}$ for the particular example in Fig 5) Each configuration will achieve a different pitch-attitude bandwidth for the $25^{\circ}$ pilot model lead compensation Following the closure of the pitch-attitude loop, the altitude loop was closed to determine the bandwidth avallable for altitude control These loop closures are identical to the previously mentioned multiloop technique and are shown in block diagram form in Fig 9

The parameter of primary interest in this technique, as before, is the altitude bandwidth The major feature of this technique, however, is the elimination of specifying an inner-loop bandwidth and the emphasis upon level I inner-loop attitude compensation If the pilot cannot attain adequate altitude bandwidth with a reasonable amount of pitch-attitude compensation, the pilot ratings will suffer Therefore, altitude bandwidth attained with pilot compensation in pitch that corresponds to good flying qualities will be a measure of flare and landing flying qualities Figure 12 illustrates the relationship between the altitude bandwidth using this technique and the actual pilot ratings for this database Again, the configurations from Table 2 are included in Fig 12 The results in Fig 12 indicate a distinct relationship between altitude bandwidth and actual pilot ratings. The \pm 1 pllot rating bounds result in a data correlation of $73 \%$, which is significantly higher than the pilot rating correlations found with altitude rate or pitch attitude. These results also show good continulty and separation throughout the bandwidth range, unlike the results in Fig 11 which are based upon the constant inner-loop/bandwidth approach The basic configurations with pitch-rate feedback (sets 1,2,6-1) show a lower altitude bandw1dth than the same configurations with the lead/lag prefilter (sets 4,5,6-2) The "conventional" configuration (set 7) displayed one of the higher attainable bandwidths The Shuttle-like configurations (set 8) displayed some of the lower bandwidths, with some exceptions noted The Shuttle1 ike canard configuration (8-4-6) was assigned a pilot rating of 1 and had the highest attainable 
altitude bandwidth $(2.5 \mathrm{rad} / \mathrm{sec})$. Another Shuttle-like configuration with a washout filter (8-3-5-1) was assigned a pilot rating of 2 , but had a very low bandwidth The remaining washout configurations appear to correlate well. The configurations from Table 2 correlated very well with the other data in Fig. 12 The overall trend in Fig. 12 shows that a minimum altitude bandwidth of $04 \mathrm{rad} / \mathrm{sec}$ appears to be necessary for level I pllot performance. It should also be noted that, although the overall correlation of data with this technique is better than that of Ref. 4, the level I boundary for bandwidth is similar (0 $5 \mathrm{rad} / \mathrm{sec}$ in Ref. 4)

The relationship between the inner-loop pitch-attitude bandwidth and the outer-loop altitude bandwidth from $F i g ~ 12$ is worth noting, as shown in F18. 13 It appears that good altitude bandwidth requires good inner-loop pitch attitude bandwidth, which is to be expected. The capabilities of modern control systems allow considerably more variation in altitude bandwidth for a given attitude bandwidth than has been possible in the past. As a result, attitude control cannot be used without consideration of the altitude response

\section{Conclusions}

Three frequency-domain handling qualities criteria were applied to the observed data to correlate the actual pilot ratings assigned to generic transport configurations with stability augmentation during the longitudinal landing task The criterla were based on closed-loop techniques using pitch attitude, altitude rate at the pilot station, and altitude at the pilot station as dominating control parameters during this task The application of these criteria to the observed data have produced the following conclusions

1) The Neal-Smith analysis using pitch att1tude did not correlate well with the observed data. The amount of pilot lead compensation in pitch attitude required by the Neal-Smith analysis was compared with the actual pilot ratings and a data correlation of $55 \%$ within \pm 1 pilot rating resulted These results indicated that pitchattitude control may not be the primary task of the pilot in landing a highly augmented generic transport aircraft

2) Altitude rate was evaluated using the Neal-Smith analysis Again, the amount of lead compensation required by the Neal-Smith analysis was compared wiuh the actual pilot ratings and a data correlation of $60 \%$ within \pm 1 pilot rating resulted. This is slightly better than that determined from pitch attitude Despite this point, it appears that altitude rate control may not be the primary task of the pilot in landing a highly augmented generic transport aircraft.

3) Altitude control performed by closing an inner loop on pitch attitude and closing an outer loop on altitude produced the most promising results. This method assumed that the pilot will provide an amount of inner-loop pitch-attitude compensation consistent with level I handling qualities and then examine the resulting altitude outer-loop performance As a result, a data correlation of $73 \%$ within \pm 1 pilot rating was determined from altitude bandwidth A minimum altitude bandwidth of $04 \mathrm{rad} / \mathrm{sec}$ appeared necessary for level I performance.

The capabilities of modern control systems allow considerably more variation in altitude bandwidth for a given attitude bandwidth than has been possible in the past As a result, attitude control cannot be used without consideration of the altitude response. Overall, it appears that control of altitude is a dominant task for the plot during landing

\section{References}

'Berthe, C. J, Chalk, C. R., and Sarrafian, $S$ K., "Pitch Rate Flight Control Systems in the Flared Landing Task and Design Criteria Development," NASA CR-172491, Oct. 1984.

${ }^{2}$ Neal, T. P. and Smith, R. E., "An In-Flight Investigation to Develop Control System Criteria for Fighter Airplanes," AFFDL-TR-70-74, Vols I and II, Dec 1970.

${ }^{3}$ Radford, R C, Smith, R E., and Basley, $R \quad E$, "Landing Flyıng Qualities Evaluation Criteria for Augmented Aircraft," NASA CR-163097, Aug 1980

${ }^{4}$ Weingarten, $\mathrm{N}$ C and Chalk, C. R, "In-Flight Investigation of Large Alrplane Flyıng Qualities for Approach and Landing," AFWAL-TR-81-3118, Sept. 1981

5 "Military Specification Flyıng Qualities of P1loted A1rplanes," MIL-F-8785C, Nov 1980 


\begin{tabular}{|c|c|c|c|c|c|c|c|c|c|}
\hline \multirow[b]{2}{*}{ Configuration ${ }^{b}$} & $\frac{q}{F}$ & $=\frac{l s}{1 s}$ & $\frac{\left.K_{I}\right)(s}{\left.\lambda_{2}\right)(\omega}$ & $\frac{+1 / T_{\theta 2}}{s p \cdot P_{s p}}$ & $\left.\frac{2}{p}\right) \frac{(s}{(s}$ & $\frac{\left.1 / T_{Z}\right)}{\left.1 / T_{F}\right)}$ & $\begin{array}{l}\text { (s+ } \\
\text { was }\end{array}$ & $\begin{array}{l}\overline{T_{\text {wo }}{ }^{\prime}} \\
\text { lout }\end{array}$ & \multirow{2}{*}{$\begin{array}{l}\text { Cooper-Harper } \\
\text { pilot ratings }\end{array}$} \\
\hline & $\mathrm{K}_{\mathrm{I}}$ & ${ }^{1 / T_{\theta 2}}$ & $\lambda_{2}^{\prime}$ & ${ }^{\prime} \omega_{n s p}{ }^{\prime}$ & $\left.\zeta^{\prime} \mathrm{sp}\right)$ & $1 / T_{Z}$ & $1 / \mathrm{T}_{\mathrm{F}}$ & $1 / T_{\text {wo }}$ & \\
\hline $1-1-1$ & 2.0 & 0.38 & 044 & 2.79, & 0.8 & $\cdots$ & -- & -- & 5,7 \\
\hline$(1-2-2)$ & 2.0 & 072 & 0.82 & 2.76 , & 08 & - & $\cdots$ & $\cdots$ & $55,7,8$ \\
\hline $1-3-7$ & 2.0 & 100 & 1.19 & 273 , & 08 & - & $\rightarrow$ & $\infty$ & $3,4,7$ \\
\hline $2-1-1$ & 2.0 & 0.38 & 050 & 178 . & 0.6 & -- & $\rightarrow$ & -- & $5,6,7$ \\
\hline $2-2-2$ & 20 & 072 & 0.93 & 1.75, & 06 & - & $\cdots$ & $\rightarrow$ & 3,45 \\
\hline $3-1-3$ & 0 & 0.38 & 2.50 & 0.036 , & 4.94 & -- & $\cdot-$ & $\rightarrow$ & $5.5,6$ \\
\hline $3-2-4$ & 0 & 072 & 2.50 & 0063. & 524 & - & $\cdots$ & -- & 25,5 \\
\hline $4-1-1$ & 2.0 & 0.38 & 0.44 & 279, & 0.8 & 0435 & 2.0 & - & 25,5 \\
\hline $4-2-2$ & 2.0 & 072 & 119 & 2.73 , & 08 & 0821 & 20 & - & 2,3 \\
\hline$(4-3-7)$ & 2.0 & 100 & 1.19 & 273 , & 0.8 & 119 & 2.0 & - & 7 \\
\hline $4-3-7-1$ & 2.0 & 100 & 119 & 273 , & 08 & 119 & 20 & 020 & 4 \\
\hline $5-1-1$ & 2.0 & 0.38 & 050 & 1.78, & 06 & 0.50 & 20 & $\cdots$ & $4.5,4.5$ \\
\hline $5-2-2$ & 2.0 & 072 & 093 & 175 , & 06 & 0.931 & 20 & -- & 2,3 \\
\hline $6-1-1$ & 30 & 038 & 0.45 & 227 , & 046 & -- & - & - & $3,5,6,6$ \\
\hline $6-1-1-1$ & 30 & 038 & 045 & 227 , & 046 & $\rightarrow$ & -- & 0.20 & 3 \\
\hline $6-2-1$ & 3.0 & 0.38 & 0.45 & 2.27, & 0.46 & 0.448 & 3.0 & -- & $2,5,5$ \\
\hline $6-2-1-1$ & 3.0 & 038 & 045 & 227 , & 0.46 & 0448 & 30 & 0.20 & 3 \\
\hline $7-1-4$ & -- & 072 & 0 & 284, & 0.80 & -- & - & $\cdots$ & 25,3 \\
\hline $8-1-5$ & 20 & 040 & 0.586 & 145 , & 050 & 06 & 20 & - & $4,55,6$ \\
\hline $8-1-5-1$ & 2.0 & 0.40 & 0586 & 1.45, & 050 & 0.6 & 20 & 020 & 2 \\
\hline $8-2-5$ & 2.0 & 0.40 & 070 & 109 , & 050 & 1.0 & 20 & - & $7,8,8$ \\
\hline$(8-2-5-1)$ & 20 & 040 & 070 & 1.09 , & 050 & 10 & 20 & 020 & 7 \\
\hline $8-3-5$ & 20 & 040 & 0586 & 145, & 050 & 15 & 20 & - & $5,7,7,8$ \\
\hline $8-3-5-1$ & 20 & 040 & 0586 & 145 , & 050 & 15 & 20 & 020 & 3,3 \\
\hline $8-4-6$ & 20 & 040 & 0590 & 147, & 060 & 06 & 20 & -- & 1 \\
\hline $8-5-5$ & 20 & 0.40 & 0586 & 145, & 050 & 06 & 20 & -- & 5,7 \\
\hline
\end{tabular}

$\mathrm{a}_{\text {Feel system }}=\left(\begin{array}{llll}21 & 0,0 & 60\end{array}\right)$

Actuator $=(27.0,070)$

$b_{\text {First number of each configuration refers to the set number }}$

( ) indicate data considered suspect, not included in analysis 
Table 2 Large Aircraft Configuration Summary (Ref. 4)

\begin{tabular}{|c|c|c|}
\hline Configuration & Description & $\begin{array}{l}\text { Cooper-Harper } \\
\text { pllot ratings }\end{array}$ \\
\hline LA12 & Short-aft tall, medium $\alpha$ feedback & 10 \\
\hline LA 13 & Short-aft tall, high a feedback & 9,8 \\
\hline LA13A & $\begin{array}{l}\text { Short-aft tali, high a feedback } \\
\text { (elfferent stick feel system than LA13) }\end{array}$ & 10 \\
\hline LA 14 & Short-aft tall, thedium q feedback & 9 \\
\hline LA15 & Short-aft tall, high q feedback & 9 \\
\hline LA15A & $\begin{array}{l}\text { Short-aft tall, high q feedback } \\
\text { ( } 1_{1} \text { fferent stick feel system than LA15) }\end{array}$ & 6 \\
\hline
\end{tabular}

a Refers to ratings assigned to landing task onl $f$

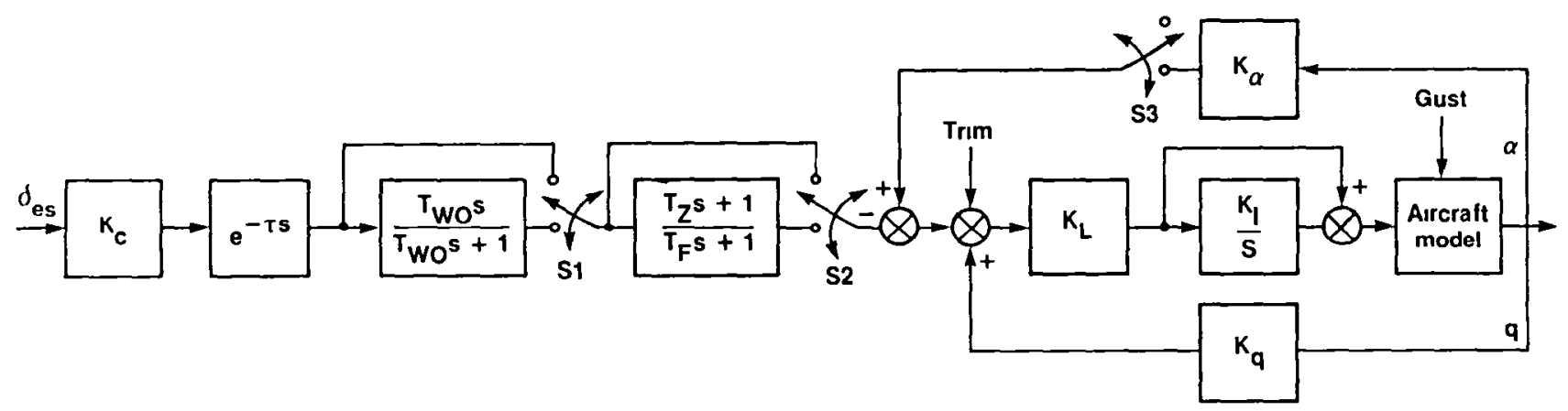

Frg. 1 Putch-rate finght-control system (Ref. 1).

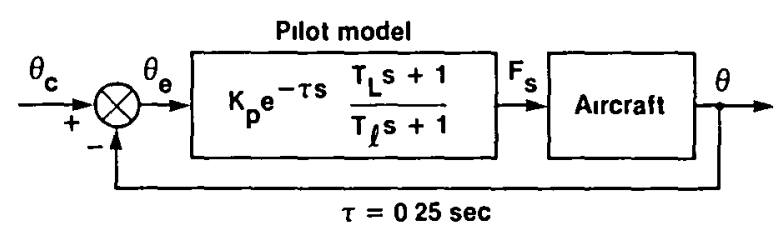

Fig. 2 Classical Neal-Smith closure technque. 

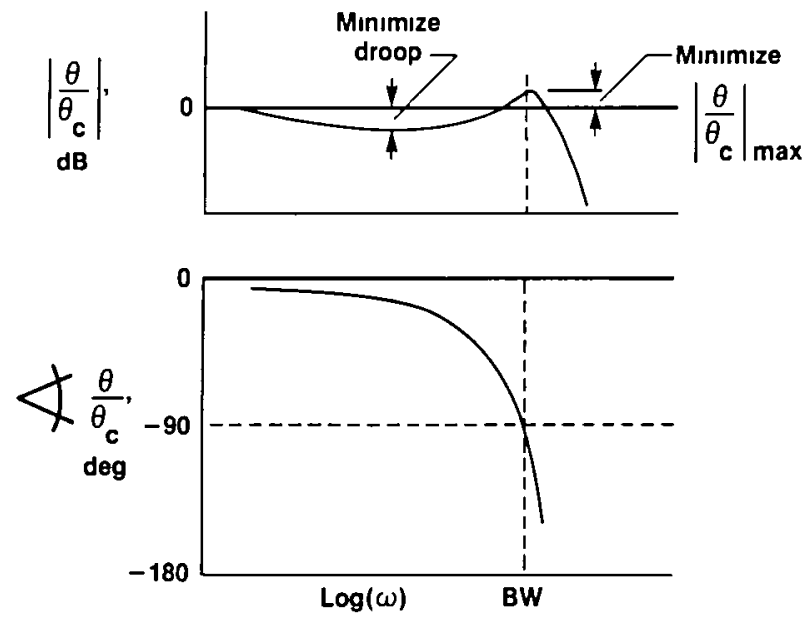

Fig. 3 Neal-Smith pilot strategy (closed-loop prlot/vehrcle frequency response).

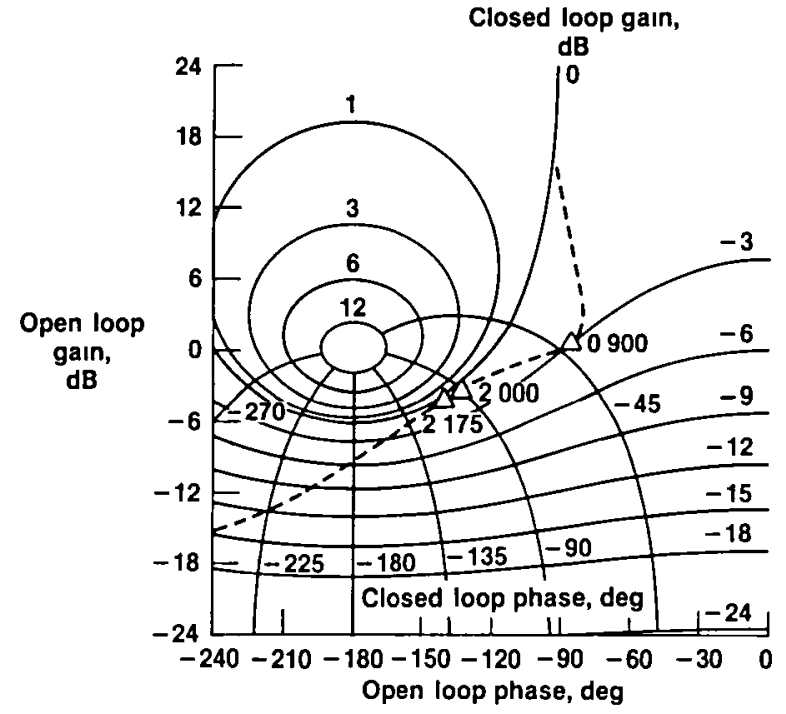

Fig. 4 Neal-Smith solution. Bandwidth $=$

$2.0 \mathrm{rad} / \mathrm{sec}$. Dashed 11 ne represents closed-1oop pilot/vehicle pitch attitude frequency response.

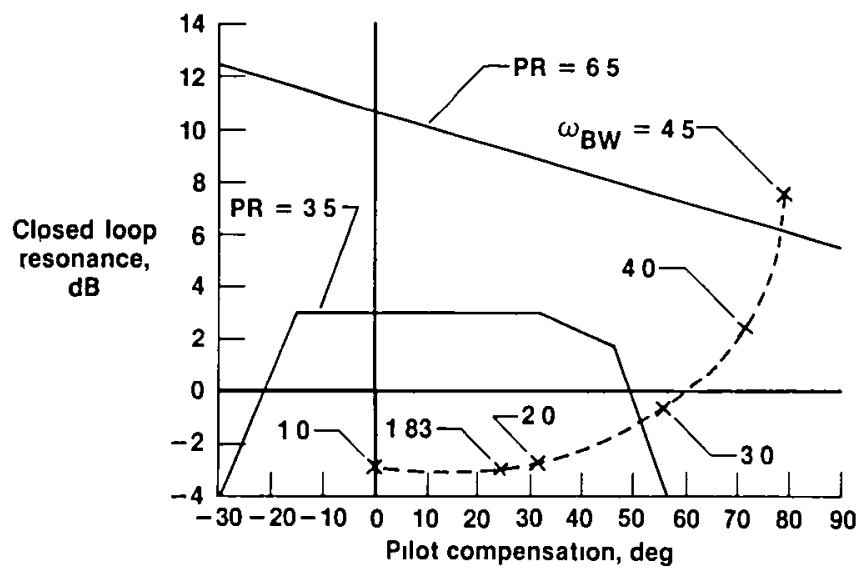

Fig. 5 Neal-Smith solution (Neal-Smith parameter plane). 


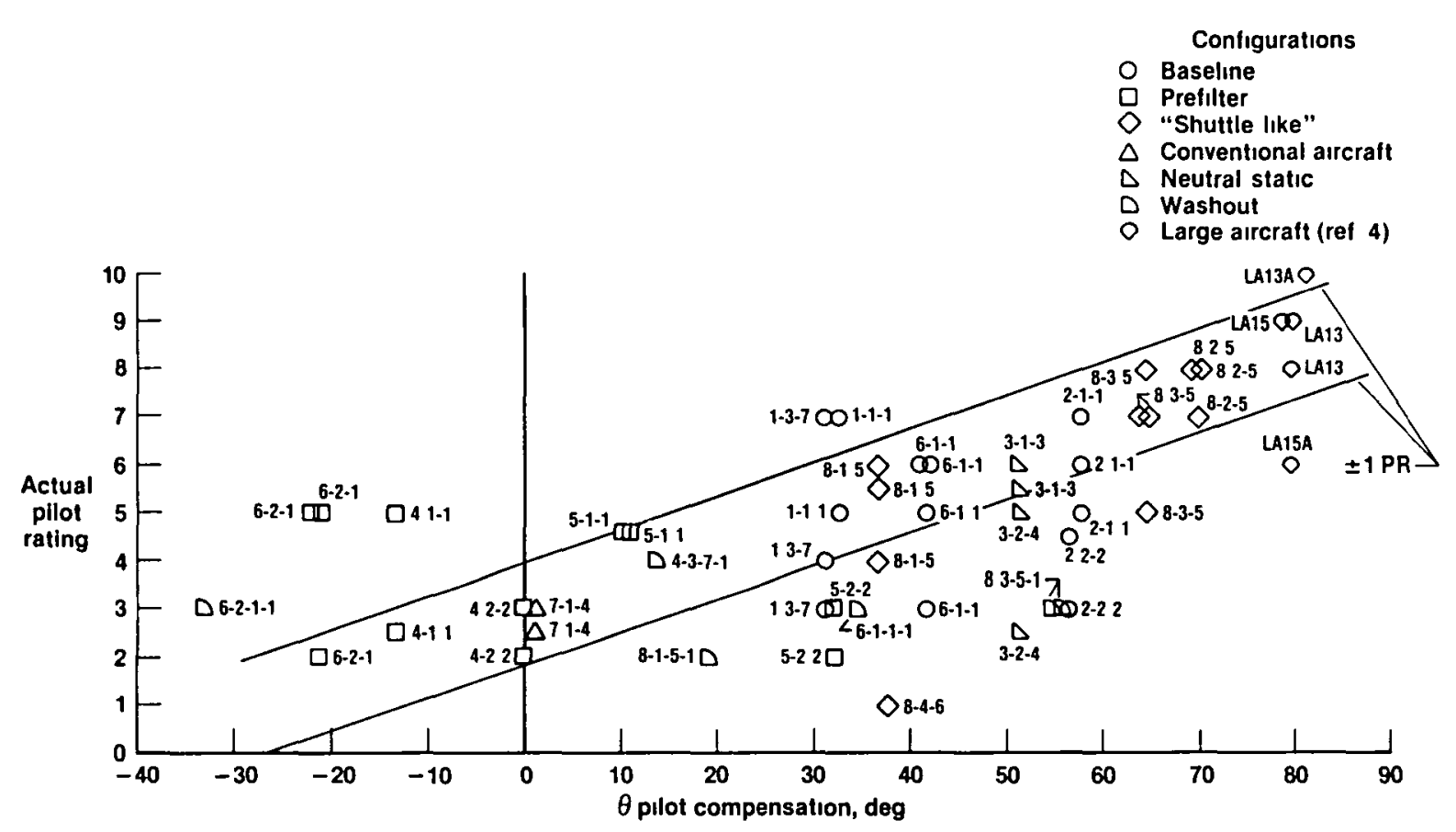

Fig. 6 Prlot rating as a function of $\theta$ prlot compensation. $W_{B W_{\theta}}=2.0 \mathrm{rad} / \mathrm{sec}$.

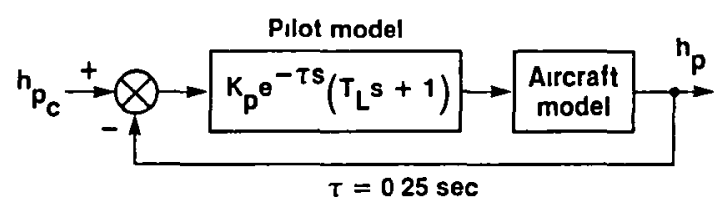

Fig. 7 Altitude rate (pilot) closure technique.

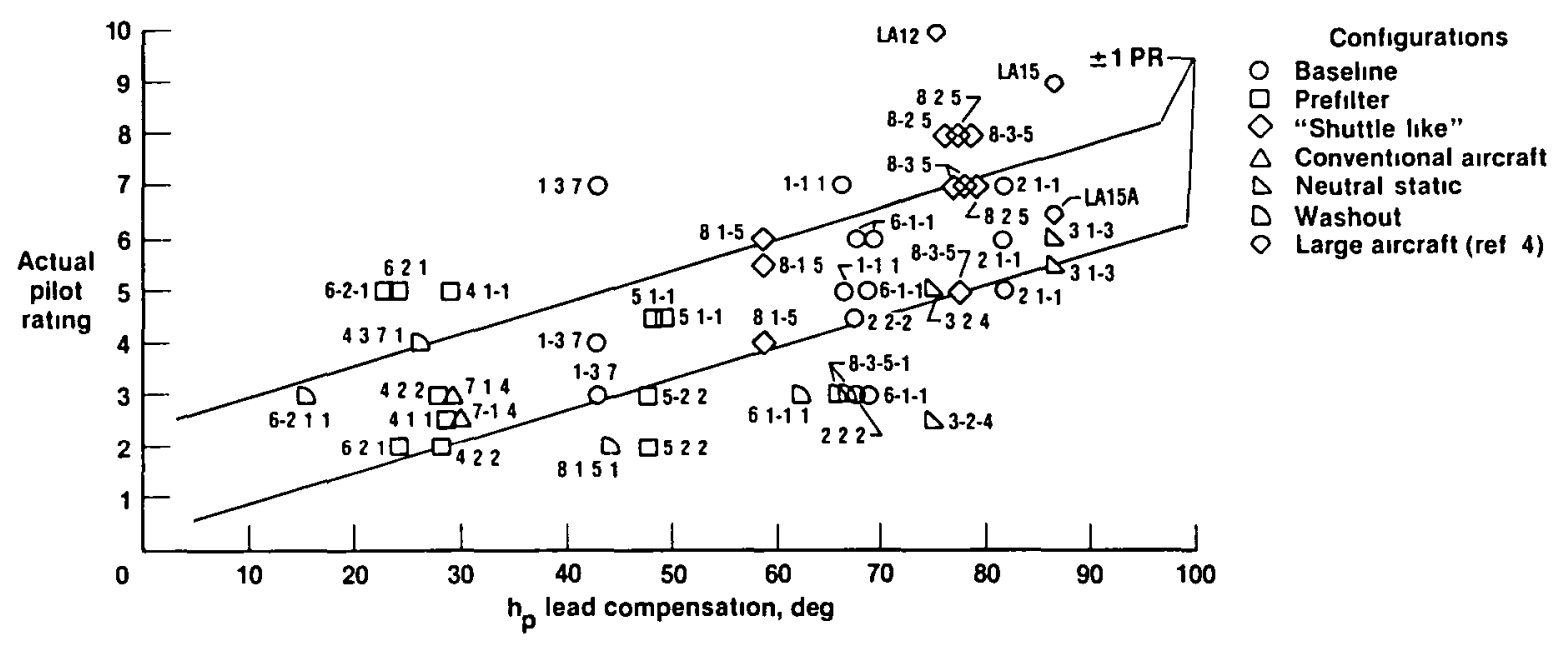

Fig. 8 Pilot rating as a function of $h_{p}$ pilot compensation. $W_{B W} h_{p}=1.3 \mathrm{rad} / \mathrm{sec}$. 


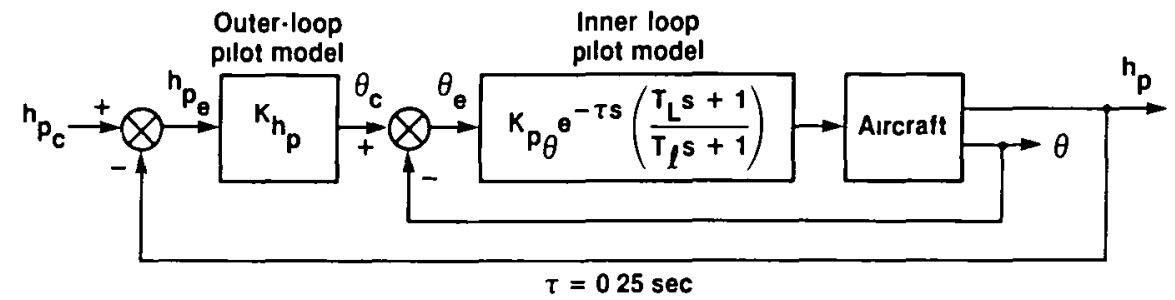

Fig. 9 Altitude outer-loop closure technique with attrtude inner-loop closure (a lead $\left.25^{\circ}\right)$.

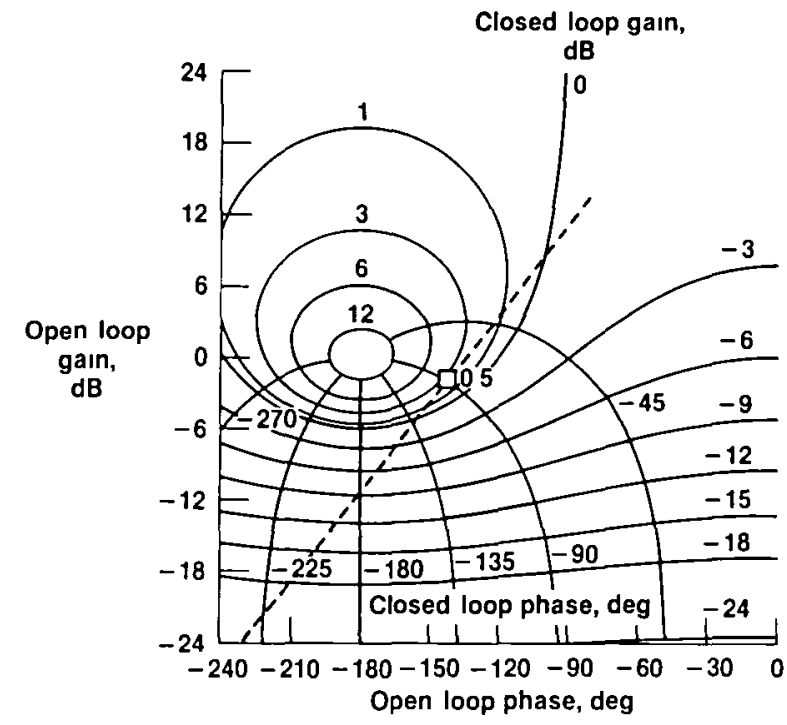

Fig. 10 Altitude outer-loop closure wrth pitchattitude inner-loop closed $\left(W_{B W_{p}}=0.5 \mathrm{rad} / \mathrm{sec}\right)$.

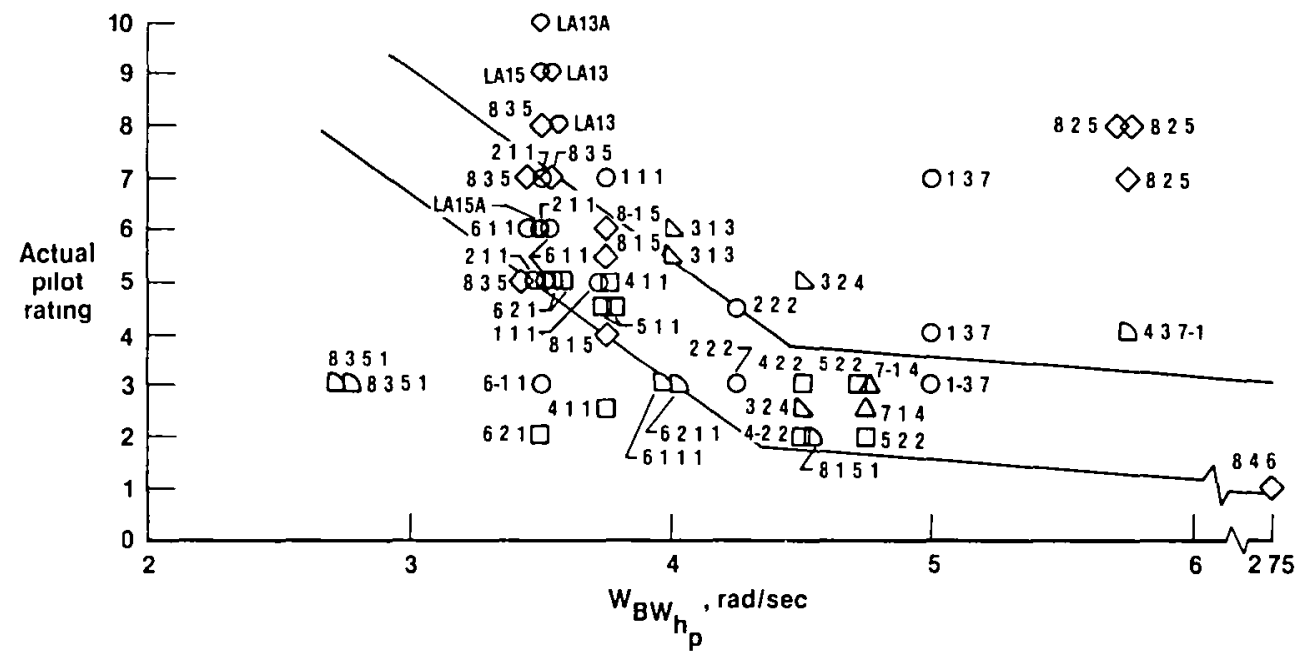

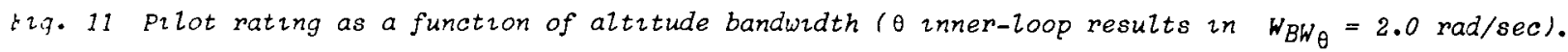




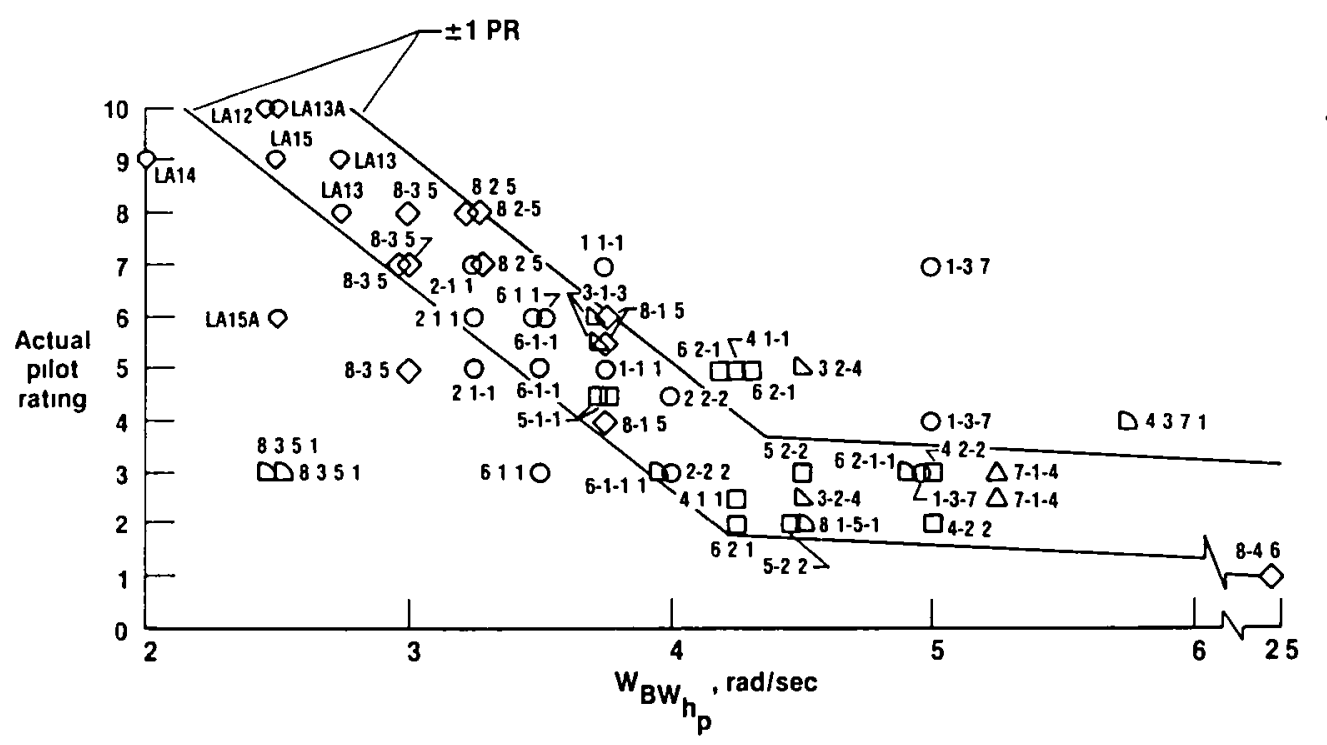

$\checkmark$ "Shuttle like"

$\triangle$ Conventional aırcraft

$\Delta$ Neutral static

- Washout

- Large aircraft (ref 4)

Fig. 12 Pilot rating as a function of altıtude bandwrdth ( $\theta$ inner-loop results in $25^{\circ}$ lead compensatzon).

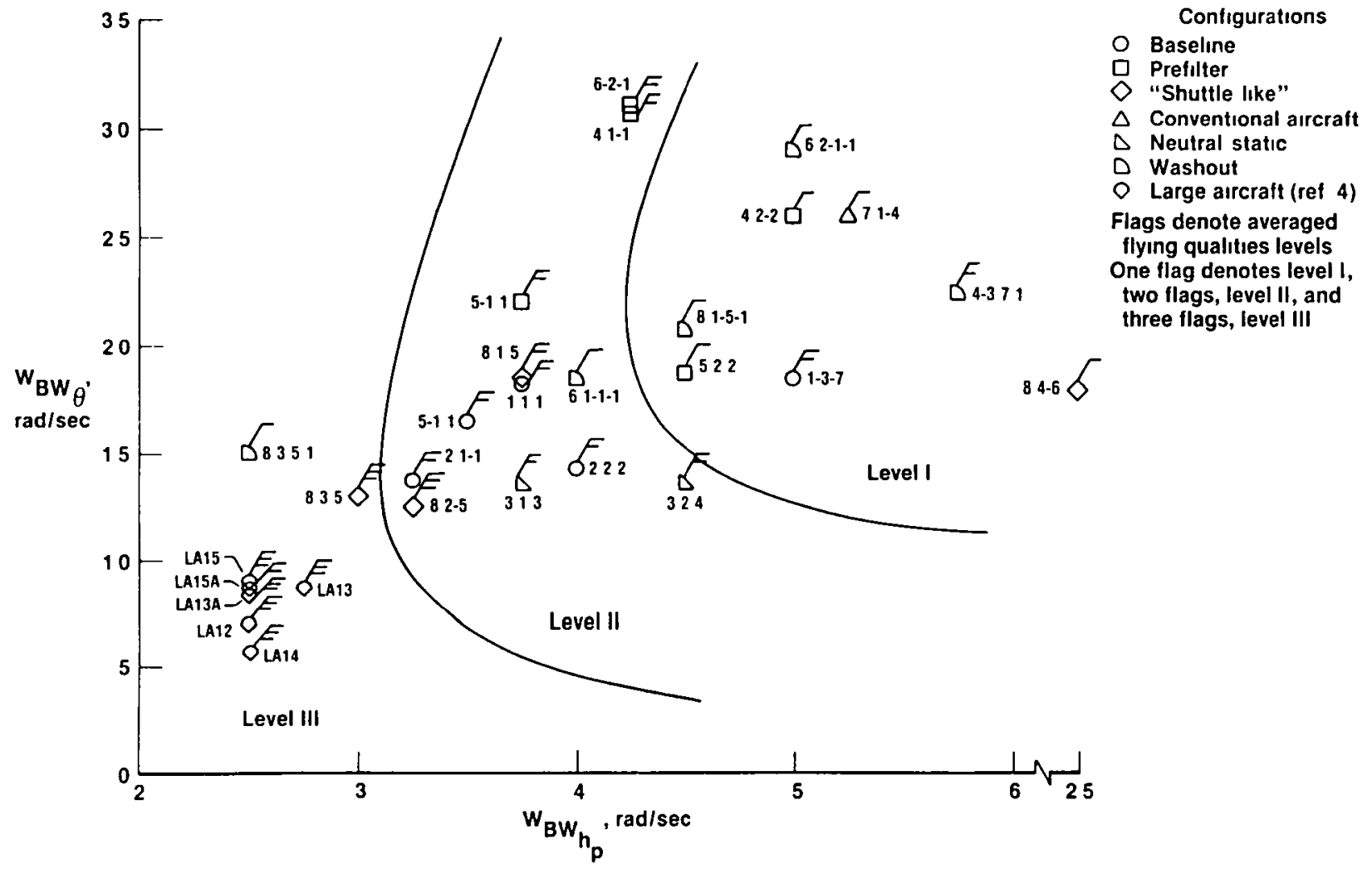

Fig. $13 W_{B W_{\theta}}$ as a function of $W_{B W_{p}}$ (results from Fig. 12$)$. 


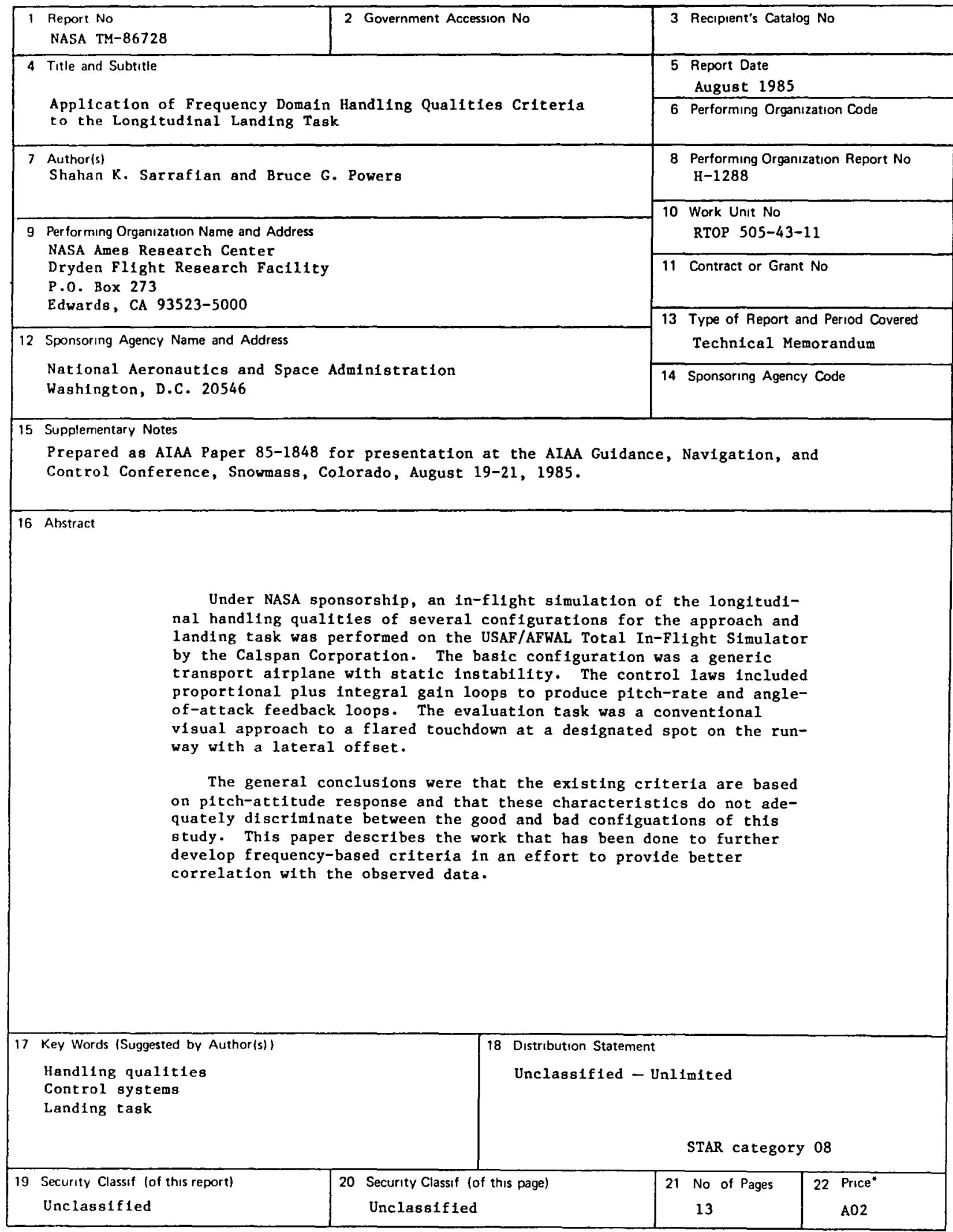

*For sale by the National Technical Information Service, Springfield, Virginia 22161. 


\section{End of Document}

